\title{
STEAM NA EDUCAÇÃO INFANTIL: UMA PRÁTICA PEDAGÓGICA QUE FOMENTA O PROTAGONISMO DA CRIANÇA NO SEU PROCESSO DE APRENDIZAGEM.
}

\author{
Juliana Martins Batista \\ Universidade do Vale do Itajaí \\ Itajaí/SC, Brasil \\ julianabatista19@hotmail.com
}

\author{
Marilei Alves \\ Universidade do Vale do Itajaí \\ Itajaí/SC, Brasil \\ advmarilei@gmail.com
}

\author{
Rodrigo Levi Rufca \\ Universidade do Vale do Itajaí \\ Itajaí/ SC, Brasil \\ r.levi@univali.com
}

\begin{abstract}
The main objective of this research was to analyze the STEAM as a learning practice that promotes protagonism, as well as its contributions in Early Childhood Education. This reflection aims to point out some innovative theories and/or teaching methodologies that contribute to the insertion of STEAM in the action with young children (aged four to five years and eleven months) to create experiences that contemplate them entirely, where they can have a voice and turn, in order to understand whether child protagonism is being opportunistic.
\end{abstract}

\section{KEYWORDS:}

Educação Infantil; Abordagem STEAM; Protagonismo Infantil.

\section{Introdução}

O contexto da Educação Infantil é permeado por interações e brincadeiras, para assegurar à criança o que chamamos de direito à infância. A BNCC contempla as competências gerais da Educação Básica, bem como os direitos de aprendizagem e desenvolvimento visando assegurar, na Educação Infantil, que as crianças aprendam a desempenhar um papel ativo, vivenciando desafios e resolvendo-os, a fim de construir significados sobre si, os outros e o mundo social e natural [1].

Nesta etapa de ensino há necessidade de favorecer e fomentar cada vez mais um aprendizado ativo, visando a formação de sujeitos criativos. Considerando isso, a proposta desta pesquisa foi refletir sobre a abordagem STEAM sigla em inglês, para Ciências, Tecnologia, Engenharia, Artes e Matemática, enquanto prática de aprendizagem que fomente o protagonismo infantil.

O que nos leva a averiguar uma proposta pedagógica que favoreça o desenvolvimento de habilidades, como aprender a aplicar conhecimentos em problemas do cotidiano; conseguir resolver, planejar e avaliar suas ações, saber comunicar ideias, desejos e sentimentos, interagir e trabalhar em conjunto através de estratégias de aprendizagens ativas contempladas na abordagem STEAM.

Diante disto, percebemos o quanto se faz necessário refletir sobre a ação educativa, propondo vivências e experiências significativas, que fomentem uma aprendizagem ativa, permitindo que o sujeito se torne autônomo e protagonista no processo de construção do seu conhecimento.

\section{STEAM, conceito e características:}

O STEAM é um acrônimo associado à educação, composto pela integração de conhecimentos como Ciência, Tecnologia, Engenharia, Artes e Matemática. Essa abordagem se originou nos Estados Unidos nos anos 90, visando garantir mão de obra qualificada nesses segmentos, sendo uma estratégia vinda de fora da escola para o espaço educativo.

No estabelecimento de ensino, o STEAM é uma abordagem que visa explorar os objetivos de aprendizagens, desenvolvendo competências e habilidades, por meio de uma participação ativa desde a Educação Infantil ao Ensino Médio. Como apontam Bacich e Holanda, nas etapas da educação básica é uma grande oportunidade da inserção da abordagem STEAM nas propostas pedagógicas e nos currículos alinhados à BNCC, sendo que os projetos STEAM geram propósito à medida que partem da realidade dos educandos [2].

Associando as diferentes áreas de conhecimento, com a uma aprendizagem baseada em projetos (ABP), pode-se possibilitar ao educando o desenvolvimento de competências como: criatividade, pensamento crítico, comunicação e colaboração.

O STEAM pode ser trabalhado em sala de aula de diversas formas, uma delas é através de projetos transdisciplinares.

Para Bacich e Holanda, um projeto STEAM, tem como objetivo a construção de propostas de intervenção pelos estudantes, para pensar sobre um desafio que faz parte do contexto escolhido, perpassando por várias áreas de conhecimentos [2].

O STEAM é uma forma de engajar e se empenhar naquilo que nos mobiliza, enquanto podemos vivenciar a interação de diferentes campos do conhecimento, visando desenvolver novos saberes, a partir de descobertas significativas, levando em consideração o contexto específico dos alunos.

O trabalho com STEAM, possui em seu contexto elementos básicos, como questão norteadora, pesquisa, levantamento de ideias e produtos. A prática desenvolvida pode estimular o aprender a conviver em grupo, e, pode favorecer uma aprendizagem por experimentação, considerando cinco etapas: 
investigar, descobrir, conectar, criar e refletir sobre a sua realidade.

Embora a BNCC não mencione o termo STEAM, a autora Pugliese menciona esta como "compatível ao discurso do STEAM, uma vez que se alinha com as habilidades do século XXI, a BNCC tem alguns elementos em comum com o movimento STEAM, além, do fato de deixar de ver o conhecimento como algo disciplinar." [3]

Nas vivências experimentais, encontramos o "S" do STEAM, Science, como prática pedagógica investigativa na área da Ciência, onde é possível pesquisar e identificar fenômenos, realizar uma observação sobre a natureza, colaborando sobre a visão ligada a temas relevantes, visando a formação integral da criança.

Pensando na Tecnologia e Engenharia no STEAM, são encontrados elementos como: mundo digital, jogos, robótica, programação, prototipação. Vivências que colaboram com o raciocínio lógico e ocupacional, visando soluções que muitas vezes podem ser aliadas ao "faça você mesmo".

Nessa abordagem a Arte vai muito além do design, esta ajuda a ciência de modo significativo, com contribuições estéticas, no fazer e no explorar a criatividade, na confecção do protótipo ou experimentações, a partir das hipóteses com um olhar diferenciado sobre o problema em questão.

No " $M$ " de matemática percebe-se que é possível desenvolver uma mentalidade matemática, a partir de dilemas reais, situações de dificuldades, favorecendo a resolução de problemas, onde envolva o investigar; concluir; argumentar; observar; conferir e reconhecer padrões e dados; criar hipóteses; testar; criar e aprender; desenvolver estratégias de cálculos, algoritmos, construindo um pensamento computacional.

Ainda no STEAM, podemos ver aspectos ligados à aprendizagem socioemocional, conseguindo dialogar com outras competências, possibilitando experiências para saber lidar com os sentimentos diante das experiências desenvolvidas, trabalhando o pensamento crítico, autocuidado, autogestão, empatia, colaboração, resoluções de problemas do cotidiano.

Sendo assim, verifica-se que com a abordagem STEAM é possível estimular o protagonismo e autonomia através de uma metodologia participativa, que explora diversas áreas do conhecimento, bem como, as competências socioemocionais, visando a formação integral da criança.

\section{Estratégias do STEAM implícitas no contexto educacional de Itajaí:}

As unidades de educação infantil do município de Itajaí, públicas, têm sua concepção de criança, prática pedagógica, dentre outras normativas regidas pelas Diretrizes Curriculares Municipais da Educação Infantil de Itajaí, e pela BNCC, as mesmas, concebe a criança como protagonista [4].
O contexto da Educação Infantil é permeado pelas interações e brincadeiras para assegurar à criança a sua infância, conforme destaca as Diretrizes Curriculares Municipais para a Educação Infantil de Itajaí e o documento da BNCC, estes são fundamentais para assegurar às crianças os direitos de aprendizagem, a saber, de conviver, brincar, participar, explorar, expressar-se e conhecer-se. [1]

As brincadeiras e as interações são concebidas como eixos fundamentais do trabalho pedagógico, por intermédio das quais se tornará possível favorecer o desenvolvimento integral da criança com idade entre zero a cinco anos, em diferentes aspectos, a saber, físico, psicológico, intelectual e social, complementar à ação da família.

Verifica-se que as Diretrizes Curriculares Municipais para a Educação Infantil de Itajaí estão atreladas à BNCC, esta por sua vez pontua a importância de favorecer à criança condições para que estas aprendam em situações nas quais possam desempenhar um papel ativo em ambientes nos quais a convidem a vivenciar desafios e a sentirem-se provocadas a resolvê-los, construindo significados sobre si, os outros e o mundo social e natural [1].

Para a concretude dos objetivos no que tange ao desenvolvimento e aprendizagem das crianças, as unidades de Educação Infantil da rede municipal adotam a metodologia de Projetos em suas práticas pedagógicas. Considerando os desafios inerentes aos planejamentos para as crianças da Educação Infantil, em prol desta metodologia, aponta as Diretrizes Curriculares que a metodologia de projetos permite o trabalho de grupos de diferentes idades [4].

Verifica-se que os projetos tanto na rede municipal quanto no STEAM são desenvolvidos com base nas curiosidades das crianças ou necessidades observadas pelos educadores. Além disso, as Diretrizes Curriculares, apontam a necessidade da educação também desenvolver a inteligência emocional dos estudantes, como apregoa o STEAM [4].

É possível vislumbrar outros indícios típicos da abordagem STEAM nas práticas pedagógicas junto às crianças nas unidades de Educação Infantil, entre eles podemos citar: a busca por desenvolver habilidades e competências, incentivar a colaboração, o respeito e a parceria nas interações, na realização de vivências e experiências estimulando a sua participação; dentre outros.

Ao relacionar os projetos vislumbrados na abordagem STEAM e a metodologia de projetos desenvolvida junto às crianças da rede municipal de Itajaí também é possível verificar alguns aspectos que as diferem. Atualmente na rede municipal os projetos em andamento em sala de aula são perpassados por outros advindos da Secretaria da Educação, como destacam as Diretrizes Curriculares [4].

Este entrelaçamento de projetos causa rupturas na proposta que estava em andamento no dia a dia das crianças, sendo necessário que num curto espaço de tempo seja realizado um movimento para envolver o grupo no novo tema que elas não estavam esperando, pois, não foi introduzido à partir dos seus interesses. 
Porém, apesar de todos esses aspectos implícitos na prática pedagógica da educação infantil de Itajaí, percebemos que ainda há muito que transformar para poder implementar o STEAM no ensino do município, precisamos explorar mais as diferentes áreas do conhecimento Ciência, Tecnologia, Engenharia, Artes e Matemática de forma transdisciplinar.

Pois, mesmo explorando os objetivos de aprendizagens dispostos nos campos de experiências da BNCC, que por si só estão interligados, ou seja, acabam se conversando em nossos projetos, os aspectos ligados às áreas do conhecimento como por exemplo a Engenharia e Tecnologia, acabam sendo pouco explorados em nosso cotidiano. Algo que precisa ser repensado se buscamos desenvolver competências e habilidades pertinentes no século XXI, onde possibilitar o desenvolvimento da criança por inteiro, não podemos trabalhar mais algumas áreas e outras menos, e, sim transitar entre elas possibilitando que a criança desenvolva a proatividade, autoconhecimento, auto estima, empatia e senso de pertencimento na busca da resolução de problemas.

Desta feita, verificou-se que a inserção da abordagem STEAM na Educação Infantil favorecerá o estímulo de múltiplas habilidades nas crianças, contribuindo significativamente para o desenvolvimento das 10 competências propostas na BNCC para a Educação Básica com vistas à construção de conhecimentos, habilidades cognitivas e socioemocionais, bem como atitudes e valores que estão alinhadas à Agenda 2030 da Organização das Nações Unidas [1].

\section{O STEAM na ação junto às crianças pequenas: refletindo sobre algumas abordagens de ensino inovadoras}

\subsection{Propostas pedagógicas e seus avanços históricos:}

Falar de Educação Infantil nos remete a alguns estudiosos, filósofos que tornaram-se precursores da transformação sobre o ato de ensinar e aprender, servindo como referência no cotidiano pedagógico pelo mundo.

Ao refletir sobre a educação infantil, encontramos Friedrich Fröebel e as possibilidades de aprendizagens em jardins de infância através da diversidade de linguagens, na qual a criança pode aprender por meio da brincadeira.

Com propostas que visam uma educação humana, temos as contribuições do filósofo John Dewey, que enfatiza que os professores e os alunos são seres ativos, que aprendem nas experiências que são dispostas diante das situações problemas que merecem o seu interesse. Refletindo nesse sentido, Westbrook aponta que para John Dewey a acumulação de sabedoria que gera a resolução desses problemas [5].

Nitidamente os pensamentos de Dewey estão bem presentes na escola da atualidade, a escola como um espaço que ensinava a criança a pensar, onde os mesmos poderiam ter a possibilidade de participar das aulas, com vivências direcionadas a partir de seu interesse, onde podiam juntamente com os seus educadores colocar as suas ideias em prática, muitas vezes buscando desenvolver a resolução de problemas, propostas estas amplamente difundidas na abordagem STEAM.

Já Paulo Freire nos mostra que há necessidade de uma prática de aprendizagem significativa através do diálogo. Em sua obra Pedagogia do Oprimido [6] ele nos mostra a importância deste no processo educativo, concebendo o diálogo como um fenômeno humano, sendo explorado na prática por meio da ação e da reflexão, algo totalmente contrário à educação bancária.

Analisando ainda as teorias de aprendizagem e desenvolvimento psicológico, a fim de promover o aprendizado de forma significativa, podemos destacar os estágios do desenvolvimento infantil proposto por Jean Piaget no Construtivismo. A autora Gonzalez-Mena (2015, p. 80) apud Mooney (2000) faz uma análise sobre a teoria por trás da prática de Piaget nas brincadeiras [7].

As significativas contribuições de Vygotsky para a educação também importam ser destacadas neste contexto. Este nos mostra o indivíduo como um ser ativo e social, que pode construir saberes nas interações com outros indivíduos e o meio que o cerca, ou seja, através do contato com a cultura e mundo externo. A saber, a zona de desenvolvimento proximal, onde as crianças mais velhas podem ajudar as menores a realizar tarefas que sozinhas, elas não conseguiriam [7].

Neste sentido, importa também trazer as contribuições da Teoria Construcionista para estas reflexões. Esta teoria foi proposta pelo professor Seymour Papert, pioneiro no estudo do uso de computadores na educação. Silveira pontua sobre Papert, que a experiência prática da criança com a matemática/aritmética, permitirá um aprendizado significativo [8].

Foi possível identificar que teorias e pesquisadores diversos, influenciaram tanto a educação brasileira quanto deram origens a diferentes escolas mundo afora, às quais se tornaram referências em inovação pedagógica.

\subsection{Práticas pedagógicas inovadoras na Educação Infantil}

Ao analisar diferentes práticas inovadoras, encontramos inspiração na Pedagogia Waldorf e na escola de San Miniato para implementar a abordagem STEAM junto às crianças pequenas da Educação Infantil.

A Pedagogia Waldorf surgiu com o filósofo Rudolf Steiner, com vistas a preparação para vida, trazendo um olhar para fases da criança, concebendo cada ser de forma individual, a qual procura integrar o desenvolvimento físico, espiritual, intelectual e artístico das crianças. Elas podem encontrar no contato com a natureza, um espaço de experimentação, tendo a possibilidade de construir o seu brinquedo, pois, é respeitado seu tempo no brincar livre. 
No que tange a autonomia e a importância de dar à criança a possibilidade de ter suas próprias experiências, nos Jardins de Infância em San Miniato, encontramos situações nas quais, os estímulos permitem que as crianças se sintam interessadas a participar e aprender com as experiências [9].

Outra prática pedagógica que respeita e prioriza as experiências da criança é Reggio Emilia, Loris Malaguzzi foi o idealizador desta abordagem, esta contempla princípios como protagonismo infantil, pedagogia da escuta, pensamento crítico, dentre outros. É possível observar que a escuta é fundamental, também para o desenvolvimento dos projetos na abordagem STEAM, observa-se que a escuta ativa e colaboração são evidenciadas nesse processo [10].

Notadamente haveriam muitas outras escolas com propostas pedagógicas inovadoras a serem citadas, contudo, destacamos um ponto em comum entre as práticas apontadas e o STEAM, que vem a ser, a participação ativa das crianças em projetos, ateliês ou diferentes espaços de resolução de problemas, a que forem motivadas por seu interesse a integrar, razão, pela qual se justificaria sua propositura também na Educação Infantil.

\section{O protagonismo infantil à partir da abordagem STEAM}

Pensando em uma aprendizagem que pode criar possibilidades no ato de ensinar e aprender com abordagens participativas, Formosinho e Oliveira-Formosinho, enfatizam que Dewey e Freire são apresentados como pedagogos, que criaram alternativas relevantes e influentes à pedagogia transmissiva e à compartimentação da educação escolar [11].

Uma maneira de romper com os padrões tradicionais, e, pensar em uma educação infantil que explore uma abordagem capaz de ouvir a criança em suas experiências, podemos destacar uma prática pedagógica aliada ao STEAM.

Este, visa realizar um ensino mais humano e significativo, conseguindo evidenciar o contexto histórico social da criança, seus saberes, necessidades, desejos e particularidades, tendo como ponto de partida a investigação para desenvolver habilidades e competências, de forma dinâmica, colaborativa e participativa.

Para iniciar um trabalho envolvendo STEAM na Educação Infantil, podemos utilizar uma aprendizagem baseada em projetos (ABP), criar oficinas ou propor a resolução de problemas.

Colocando em prática uma participação mais ativa, partir do interesse da turma, para iniciar um projeto é uma ótima forma de engajar as crianças [12].

O que nos leva a perceber o quanto é válido oportunizar um ambiente inovador, onde as crianças consigam desenvolver projetos que se aproximem da realidade, onde possam aprender e desenvolver habilidades, a partir de estratégias que tem como ponto de partida a resolução de problemas. Através de projetos e estratégias construcionistas, ou seja, experiências práticas, o educador pode favorecer um aprendizado mão na massa, por meio do STEAM, proporcionando o desenvolvimento da autonomia da criança.

Logo, as vivências na Educação Infantil deverão ser pensadas para que as crianças participem ativamente, através da mediação do docente, conduzindo as crianças a problematizar aspectos da realidade.

Para Resnick há uma abordagem no jardim de infância no qual a criança pode levar para vida, enquanto brincam, elas começam a se desenvolver como pessoas criativas [13].

No espaço educativo infantil, a formação de sujeitos criativos ocorre por meio de estímulos através das brincadeiras, justamente, porque as crianças durante as brincadeiras podem se desenvolver como pensadores criativos em vivências reais do cotidiano.

Em meio ao novo modo de propor as aprendizagens com STEAM, o educador precisa impulsionar a criança a descobrir e aprender, bem como explorar a sua imaginação, sendo aquele docente que acompanha o processo de aprendizagem que está acontecendo. A sala de aula pode ser um espaço privilegiado de cocriação, Maker, de busca de soluções empreendedoras, em todos os níveis, onde estudantes e professores aprendam a partir de situações concretas, desafios, jogos, experiências, vivências, problemas, projetos [14]. Assim, cabe a nós educadores organizar vivências e experiências para ativar o processo lúdico, como espiral de aprendizagem criativa, oportunizando que a criança possa aprender fazendo [13]. $\mathrm{Na}$ abordagem STEAM com vistas ao aprender fazendo, seria importante pensar sobre a ação pedagógica e sobre a organização do espaço educativo [15]. Pois, as crianças precisam de espaço para exercerem sua criatividade, confrontar ideias e construir novos saberes [16].

Dessa forma, cabe ao docente realizar uma transição com relação ao ato de ensinar, esse processo de transformação da prática pedagógica desenvolvida pode ser iniciado com pequenas mudanças, permitindo a realização de experiências, a partir do interesse das crianças, proporcionando vivências nos diferentes grupos, promovendo interações de qualidade, criando um espaço para experimentação de diferentes linguagens no qual a criança seja protagonista.

\section{CONSIDERAÇÕES FINAIS:}

Todos os apontamentos e reflexões demonstraram que a BNCC, torna-se propositiva no que tange ao estímulo para que as crianças possam aprender sendo impulsionadas a desempenhar ações de protagonismo nas vivências realizadas, o que nos levaram a considerar que a abordagem STEAM pode ser implementada junto às crianças pequenas.

Verificou-se que nas unidades públicas de educação infantil deste município, é adotada a metodologia de Projetos, nos quais foram detectados elementos da abordagem STEAM e identificou-se alguns aspectos que as diferem. 
Neste sentido, então por que trabalhar com os projetos da perspectiva STEAM na educação infantil? A abordagem em questão vai oportunizar o desenvolvimento da criatividade e o senso crítico das crianças, pois, através da aprendizagem baseada em projeto os pequenos poderão pensar, argumentar, experienciar, interagir, criar e aprender por meio das vivências que são oportunizadas a elas.

Por meio do STEAM os professores promovem aprendizagens enriquecedoras, as crianças conseguem ampliar a sua compreensão de mundo, estimulando os pequenos a criar, investigar, experienciar vivências com "mão na massa", desenvolvendo a criatividade, autonomia e uma perspectiva criativa da tecnologia.

Além de favorecer a participação mais ativa das crianças, o trabalho com STEAM capacita o professor a trabalhar com as diferentes áreas de conhecimento, tendo mais contato com as áreas ligadas à tecnologia, engenharia e ciência, algo que é pouco explorado na educação infantil.

Embora os professores de educação infantil estejam habituados a trabalhar com projetos, com o STEAM eles conseguem propor que as crianças possam investigar, descobrir, conectar, criar e refletir.

$\mathrm{O}$ que nos levou a perceber que com as práticas inovadoras o protagonismo infantil ganhou mais espaço no processo de ensino e aprendizagem, pois, com essa participação das crianças no contexto escolar podemos desenvolver uma proatividade, um autoconhecimento, autoestima, a empatia e o senso de pertencimento, ou seja, competências emocionais e a capacidade de resolução de problemas.

Percebeu-se que para aplicar STEAM na educação infantil é necessário se distanciar totalmente do método tradicional, precisando ouvir e observar as crianças; rever os espaços, repensar sobre ele, ver a sala de aula como um espaço flexível dinâmico que possa ser propício para criar, sendo um espaço facilitador da aprendizagem com vivências mais práticas; criar oficinas para que os pequenos possam colocar em prática as hipóteses do projeto desenvolvido; envolver as crianças em problemas e desafios reais, vivências que possam desenvolver a cooperação e a empatia, promovendo interações entre as crianças $\mathrm{e}$ as áreas de conhecimento.

Enfim, foi interessante observar que apesar dos anos que separam diferentes propostas instituídas no séc. XIX e a abordagem STEAM que é do séc. XX, as mesmas defendem a aprendizagem com foco em vivências práticas que são sobretudo "mão na massa", tornando-as muito próximas e inovadoras cada uma a seu tempo e com suas especificidades. Desta feita, vimos quão significativas são as vivências da abordagem STEAM para estímulo ao aprendizado e protagonismo infantil.

\section{Referências}

[1] BRASIL. Ministério da Educação. Secretaria de Educação Básica. Base Nacional Comum Curricular para a educação infantil. Secretaria de Educação Básica. Brasília: MEC, SEB, 2017.

[2] BACICH, L. e HOLANDA, L. STEAM em Sala de Aula: A Aprendizagem Baseada em Projetos Integrando Conhecimentos na Educação Básica (Desafios da Educação). Org. Lilian Bacich, Leandro Holanda- Porto Alegre: Penso, 2020.
[3] PUGLIESE. Gustavo Oliveira. Um programa do STEAM education como tendência global. In: BACICH, L. e HOLANDA, L. STEAM em Sala de Aula: A Aprendizagem Baseada em Projetos Integrando Conhecimentos na Educação Básica (Desafios da Educação). Org. Lilian Bacich, Leandro Holanda- Porto Alegre: Penso, 2020

[4] ITAJAÍ. Diretrizes curriculares municipais para a educação infantil / Secretaria da Educação. Departamento Técnico de Educação Infantil. Universidade do Vale do Itajaí - Itajaí: UNIVALI, 2019.

[5] WESTBROOK, Robert B. John Dewey / Robert B. Westbrook; Anísio Teixeira, José Eustáquio Romão, Verone Lane Rodrigues (org.). - Recife: Fundação Joaquim Nabuco, Editora Massangana, 2010. Disponível em: <http://www.dominiopublico.gov.br/download/texto/me4677.pdf $>$ Acesso em $02 / 10 / 2020$

[6] FREIRE, Paulo. Pedagogia do oprimido. 17 . ed. Rio de Janeiro, Paz e Terra, 1987.

[7] GONZALEZ-MENA, Janet. Fundamentos da Educação Infantil: Ensinando Crianças em uma Sociedade Diversificada. 6. ed. - Porto Alegre: Penso, 2015.

[8] SILVEIRA, José De Anchieta. Construcionismo e inovação pedagógica: uma visão crítica das concepções de Papert sobre o uso da tecnologia computacional na aprendizagem da criança. THEMIS. Revista da Escola Superior da Magistratura do Ceará - ESMEC, v. 10 (2012). e-ISSN: 2525-5096. Disponível em: 〈http://revistathemis.tjce.jus.br/index.php/THEMIS/article/view/87> Acesso em: $06 / 10 / 2020$.

[9] REIS, Gisele; NEITZEL, Adair de Aguiar. Experiências Literárias com Crianças Pequenas em San Miniato. $1^{\text {a }}$ ed. Itajaí-SC, Univali, 2018.

[10] BACICH, L. Recolhendo evidências: a avaliação e os seus desafios. STEAM em Sala de Aula: A Aprendizagem Baseada em Projetos Integrando Conhecimentos na Educação Básica (Desafios da Educação). Org. Lilian Bacich, Leandro HolandaPorto Alegre: Penso, 2020.

[11] FORMOSINHO, João; OLIVEIRA-FORMOSINHO, Júlia. Pedagogia transmissíveis e pedagogias participativas nas escolas de massa. In: OLIVEIRAFORMOSINHO, J.; PASCAL, C. Documentação pedagógica e avaliação para transformar a educação infantil. Porto Alegre: Artmed, 2019

[12] CUGINOTTI. Andressa Prata Cirino. STEAM na prática: exemplos de projetos. STEAM em Sala de Aula: A Aprendizagem Baseada em Projetos Integrando Conhecimentos na Educação Básica (Desafios da Educação). Org. Lilian Bacich, Leandro Holanda- Porto Alegre: Penso, 2020.

[13] RESNICK, M. Aprendizagem criativa: por uma educação mais expressiva, mão na massa e relevante para todos. Porto Alegre: Penso, 2020.

[14] MORAN. José. Metodologias ativas para uma aprendizagem mais profunda. In: BACICH, L.; MORAN. J. (Org.). Metodologias ativas para uma educação inovadora: uma abordagem teórico-prática. Porto Alegre: Penso, 2018.

[15] CEPPI, Giulio; ZINI, Michele. Crianças, Espaços, Relações: Como Projetar Ambientes para a Educação Infantil. edição: 1. Porto Alegre: Penso, 2013.

[16] HORN, Maria da Graça Souza. Sabores, Cores, Sons, Aromas: A Organização dos Espaços na Educação Infantil. Edição: 1. Porto Alegre: Penso, 2003. 